\title{
Preliminary study on micro area based spatial distribution of powdery mildew in an organic apple orchard
}

\author{
Holb, I. J. \\ University of Debrecen, P.O. Box 36, H-4015 Debrecen, Hungary (e-mail: holb@agr.unideb.hu)
}

\begin{abstract}
Summary: In this study, the objective was to report a preliminary study on micro area based spatial distribution of powdery mildew in an organic apple orchard. Results showed that number of symptomatic plant part ranged between 11 and 20 on shoot and between 9 and 24 on fruit. Number of asymptomatic plant part ranged between 85 and 109 on shoot and between 133 and 206 on fruit. Disease incidence ranged between 13.8 and $17.6 \%$ on shoot and between 9.1 and $11.3 \%$ on fruit. Disease aggregation index ranged between 0.098 and 0.228 on shoot and between 0.043 and 0.108 on fruit. One of the four trees showed significant within canopy aggregation of disease for shoot powdery mildew symptoms in both years. For leaf powdery mildew, all tree exhibited random patterns in both years.
\end{abstract}

Keywords: Podoshphaera leucotricha, spatial pattern, organic apple

\section{Introduction}

Apple powdery mildew (Podoshphaera leucotricha) is a wordwide known fungal pathogen of apple. It is a key important fungal disease of apple which causing severe econimic loss on susceptible cultivars in every years where apple are grown (Hickey \& Yoder, 1990; Holb, 2009, 2013; Szentivanyi \& Kiss, 2003).

Spatial analysis can characterize more accurately and deeply the inner structure of epidemics in a plant stand/ orchard, which was widely studied from 1990s after the introduction of novel statistical-mathematical methods (e.g. Gibson and Austin, 1996; Gottwald, 1995; Kocks et al., 1999). Epidemics can be investigated in micro-areas for instance inside a plant/tree in any small areas (e.g. Sposito et al., 2008; Vereijssen et al., 2007). Data collected in microareas require accurate localization (such as within tree investigation) as well as show foci of epidemics and their behaviour in time, i.e. investigation can be linked in time and space.

Previous studies examining spatial disease patterns within tree canopies either divided the canopy into layers (Holb \& Scherm, 2007) or quadrats (Batzer et al., 2008; Spósito et al., 2008). However, an important limitation of using such stratification is that the associated grouping of data may fail to capture fine-scale patterns within each block. In a recent pilot study, Everhart et al. (2011) used a digitizer to map different brown rot symptom types (blossom blight, shoot blight, and twig cankers) caused by the fungal plant pathogen Monilinia laxa in individual sour cherry canopies. Microarea based spatial aspects of powdery mildew have received very little attention.

In this study, the objective was to report a preliminary study on micro area based spatial distribution of $P$. leucotricha in an organic apple orchard.

\section{Materials and methods}

\section{Orchard site}

The experiment was carried out in an organic orchard located at Eperjeske, Hungary. The orchard was planted with cultivars Mutsu, Jonathan, Prima on M26 rootstocks in 1997. The distance between rows was $5 \mathrm{~m}$, and the distance between trees within a row was 2 . The orchard was treated according to the Hungarian Organic Growing Guidelines derived from the IFOAM guidelines. The micro-area based spatial experiment was set in 2013 and 2014.

\section{Assessment of spatial pattern of symptoms}

At harvest, fruit and shoot symptom caused by $P$. leucotricha was present and readily distinguishable. Four trees (Table 1) of different sizes and with varying levels of disease incidence were selected for digitizing. The $x, y$ and $\mathrm{z}$ co-ordinates of all symptomatic elements were digitized, as were all asymptomatic (healthy) shoot and fruit (Table 1). Each digitized canopy element was tagged with coloured tape to ensure that points were not measured twice and that no relevant point was omitted. Disease incidence of shoot and fruit was also measured also for each tree.

\section{Spatial pattern analysis}

Spatial patterns of aggregation for a given symptom type within the canopy were characterized based on nearest neighbour distances, i.e. the shortest Euclidian distance between symptoms derived from the $\mathrm{x}, \mathrm{y}$ and $\mathrm{z}$ co-ordinates of points. The frequency distribution of nearest-neighbour distances within each tree could then be used to determine deviation from randomness. 
Disease aggregation index (dw) was also determined. The test statistic dw, the maximum departure of the observed cumulative frequency distribution. Values of $d w$ represents the index of disease aggregation and is calculated based on the cumulative frequency distribution of nearest-neighbour distances among powdery-mildew affected shoot and fruit. Significant positive values indicate aggregation, whereas significant negative values correspond to a more regular distribution compared with the random simulation.

\section{Results}

\section{Disease pattern}

Number of symptomatic plant part ranged between 11 and 20 on shoot and between 9 and 24 on fruit (Table 1). Number of asymptomatic plant part ranged between 85 and 109 on shoot and between 133 and 206 on fruit. Disease incidence ranged between 13.8 and $17.6 \%$ on shoot and between 9.1 and $11.3 \%$ on fruit.

Table 1. Summary of symptomatic patterns on fruit and shoot disease incidence of powdery mildew on 4 apple trees within the tree canopy (Eperjeske 2013 and 2014)

\begin{tabular}{|c|c|c|c|}
\hline No of tree & $\begin{array}{c}\text { No of } \\
\text { symptomatic } \\
\text { plant part }\end{array}$ & $\begin{array}{c}\text { No } \\
\text { asymptomatic } \\
\text { plant part }\end{array}$ & $\begin{array}{c}\text { Disease } \\
\text { incidence (\%) }\end{array}$ \\
\hline \multicolumn{4}{|c|}{$2013-2014$, shoot } \\
\hline I & 15 & 85 & 17.6 \\
\hline II & 11 & 97 & 15.5 \\
\hline III & 20 & 109 & 13.8 \\
\hline III & 16 & 97 & 15.5 \\
\hline I & $2013-2014$, fruit & 9.1 \\
\hline II & 24 & 165 & 7.3 \\
\hline III & 11 & 149 & 11.3 \\
\hline III & 20 & 206 & 133 \\
\hline
\end{tabular}

\section{Disease aggregation}

Disease aggregation index ranged between 0.098 and 0.228 on shoot and between 0.043 and 0.108 on fruit (Table 2). One of the four trees showed significant within canopy aggregation of disease for shoot powdery mildew symptoms in both years (Table 2). For leaf powdery mildew, all tree exhibited random patterns in both years.

\section{Conclusions}

Spatial disease incidence of apple powdery mildew on leaf and fruit did not reached $20 \%$ in the two years. Most diseased shoots caused by $P$. leucotricha were not aggregated within the tree and none of the diseased leaves were aggregated.
Table 2. Summary of disease agrregation index and spatial patterns for powdery mildew symptoms on 4 apple trees within the tree canopy (Eperjeske 2013 and 2014)

\begin{tabular}{|c|c|c|l|}
\hline No of tree & $\begin{array}{c}\text { Disease } \\
\text { aggregation } \\
\text { index (dw) }\end{array}$ & P value & Spatial pattern \\
\hline \multicolumn{4}{|c|}{$2013-2014$, shoot } \\
\hline I & 0.124 & 0.119 & random \\
\hline II & 0.098 & 0.432 & random \\
\hline III & 0.228 & 0.046 & aggregated \\
\hline IV & 0.101 & 0.234 & random \\
\hline \multicolumn{5}{|c|}{$2013-2014$, fruit } \\
\hline I & 0.087 & 0.543 & random \\
\hline II & 0.054 & 0.654 & random \\
\hline III & 0.043 & 0.765 & random \\
\hline IV & 0.108 & 0.201 & random \\
\hline
\end{tabular}

$\mathrm{dw}$ represents the index of disease aggregation and is calculated based on the cumulative frequency distribution of nearest-neighbour distances among powdery mildew-affected shoot and fruit. Significant positive values indicate aggregation, whereas significant negative values correspond to a more regular distribution compared with the random simulation. Significant dw values $(\mathrm{P} \leq 0.05)$ are in bold.

\section{Acknowledgements}

This research was supported partly by a grant of the Hungarian Scientific Research Fund (OTKA K108333), EU7 PURE programme and by the European Union and the State of Hungary, co-financed by the European Social Fund in the framework of TÁMOP-4.2.4.A/ 2-11/1-2012-0001 'National Excellence Program' under the project number: A2-SZJ-TOK-13-0061.

\section{References}

Batzer, J.C., Gleason, M.L., Taylor, S.E., Koehler, K.J. \& Monteiro, J.E.B.A. (2008): Spatial heterogeneity of leaf wetness duration in apple trees and its influence on performance of a warning system for sooty blotch and flyspeck. Plant Disease, 92: 164-170.

Everhart, S. E., Askew, A., Seymour, L., Holb, I.J. \& Scherm, H. (2011): Characterization of three-dimensional spatial aggregation and association patterns of brown rot symptoms within intensively mapped sour cherry trees. Annals of Botany, 108: 1195-1202.

Gibson, G.J. \& Austin, E.J. (1996): Fitting and testing spatiotemporal stochastic models with application in plant epidemiology. Plant Pathology, 45: 172-184.

Gottwald, T.R. (1995): Spatiotemporal analysis and dynamics of citrus scab in nursery plots. Phytopathology, 85: 1082-1092.

Hickey, K.D. \& Yoder K.S. (1990): Apple powdery mildew. Pages 9-10 [In A.L. Jones and H.S. Aldwinckle, ed. Compendium of Apple and Pear Diseases.] Am. Phytopathol. Soc., St. Paul, MN. 100 pp.

Holb, I.J. (2013): Apple powdery mildew caused by Podosphaera leucotricha: some aspects of biology. International Journal of Horticultural Science, 19 (3-4): 19-24.

Holb, I.J. (2014): Apple powdery mildew caused by Podosphaera leucotricha:some aspects of disease management. International Journal of Horticultural Science, 20 (1-2): 29-33. 
Holb, I. J. \& Scherm, H. (2007): Temporal dynamics of brown rot in different apple management systems and importance of dropped fruit for disease development. Phytopathology, 97: 1104-1111.

Kocks, C.G., Zadoks, J.C. \& Ruissen, M.A. (1999): Spatiotemporal development of black rot (X. campestris pv. campestris) in cabbage in relation to initial inoculum levels in field plots in The Netherlands. Plant Pathology, 48: 176-188.

Sposito, M.B., Amorim, L., Bassanezi, R.B., Bergamin Filho, A. \& Hau, B. (2008): Spatial pattern of black spot incidence within citrus trees related to disease severity and pathogen dispersal. Plant Pathology, 57: 103-108.

Szentivanyi, O. \& Kiss, L. (2003): Overwintering of Ampelomyces mycoparasites on apple trees and other plants infected with powdery mildews. Plant Pathology, 52 (6): 737-746.

Vereijssen, J., Schneider, J.H.M. \& Jeger, M.J. (2007): Epidemiology of Cercospora leaf spot on sugar beet: modeling disease dynamics within and between individual plants. Phytopathology, 97: 1550-1557. 